\title{
Binomial Approach for The Valuation of Employee Stock Option with some features: Vesting Period, Exit Rate, Reload, and Reset
}

\author{
Rudianto Artiono*, Dayat Hidayat \\ Mathematics Department, Universitas Negeri Surabaya, Indonesia
}

\begin{abstract}
An Employee stock option (ESO) is one of compensation that given by company to their employee. It gives right to the employee to buy companies stock in the future with special price that have been agreed when the options were granted. In general, the valuation of ESO pricing is different with other option pricing. ESO have some features which accommodate company importance and also consider employee behavior. This article aimed to apply the binomial approach for the valuation of ESO by considering some features such as a).Vesting period, which is waiting time to exercise the option, b). Exit rate, which is feature that consider employments shock, c). Reload, a feature that give a new option after the old one had been exercised, d). Reset, a feature that doing reset on the agreement in ESO if stock in "out of money" condition. The valuation of the ESO price have been derived from the five possibility of payoff with consideration of each features involved. This study gave the valuation of ESO which consists of two areas, namely the ESO price after vesting period and ESO price at vesting period.
\end{abstract}

Keywords: Employee stock option, binomial approach, vesting period

\section{Introduction}

In the last 15 years, several companies in Indonesia have begun to develop different compensation systems for their employees. If previously the company provided compensation in the form of cash such as payroll, holiday benefits, and bonuses each year, now the company is beginning to apply non-cash compensation such as participation in pension program, participation in insurance program, participation in pilgrimage program and grant of employees stock options [1-4]. The granting of employee stock options entitles an employee to own a portion of a given company stock in the form of share options.

An employee with a stock option have right to buy a portion of the company's share within a certain period in the future at a price that has been determined at the time the option is granted [5-7]. Granting these employee stock options will provide benefits to both the company and the employee, among others: each employee will show his best performance to get this stock option, while the company can bind its best employees to stay working in the company. This employee stock option can also develop a sense of ownership company so that it can indirectly instill a sense of responsibility as well as a working spirit in employees to participate in advancing the company [8-12].

Given that the granting of employee share options is highly dependent on the interests of the company and the behavior of the employees within the company, then the pricing of employee share options is different from the pricing of options in general. There are several features that can accommodate the interests of the company and the interests of employees such as the vesting period feature. This feature can be used by companies to retain their employees to stay in the company for a certain period of time. In addition, there are still some other features that can be used by the company [13-15].

In this article, we used some features as follows: 1) Vesting period, ESO recipients can exercise after a certain period of time, 2) Exit rate, ESO pricing takes into account the possibility of employees receiving ESO out of the company either voluntarily or due to layoffs, 3) Reload, ESO recipients who have exercised their options, can receive new ESO with a certain proportion, and 4) Reset, ESO which have passed the waiting period but not excercise because in a state of out of the money can be re-arranged about the agreement contained in the ESO contract.

\section{Mathematical Model}

Figure 1 shows the payoff of ESO based on 5 possible stock price movements. At the initial time given, the ESO price is equal to $D K$. The first possibility, if the stock price hits the reset barrier so that with the reset feature, the payoff from ESO is ${ }_{\rho L} D l K$. The second

\footnotetext{
* Corresponding author : rudiantoartiono@unesa.ac.id
} 
possibility, if an employment shock occurs before this vesting period results in employees leaving the company, then the payoff from OSK is 0 (forfeited). The third possibility, if exercise is carried out immediately due to the employment shock after the vesting period but has not reached the expected exercise boundary, the payoff from OSK is $\max (S-K, 0)$. Fourth possibility, if exercised when the price of stock reaches the exercise boundary after passing the vesting period. Or the fifth possibility is exercised immediately after the option has passed the vesting period and the stock price has been above the exercise boundary. The fourth and fifth possible payoffs from OSK are $S-K+{ }_{\rho H} D K$.

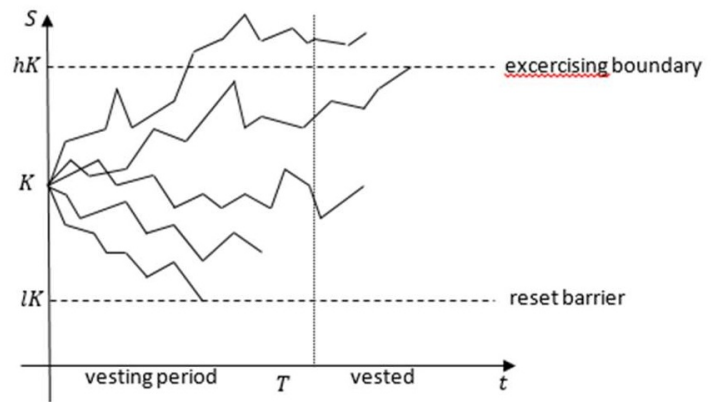

Fig. 1. Payoff Diagram of ESO

Furthermore, from the payoff that has been obtained, the ESO price will be determined at the time it was initially given. The determination of the ESO price is calculated through 2 time zones, namely the time after the vesting period and the time during the vesting period, where the valuation of the vesting period depends on the results obtained when calculating the ESO price after the vesting period.

\subsection{Binomial Approach for ESO}

The use of notation in the valuation ESO prices uses the standard notation in the binomial method except for the notation of the vesting period. The notation $T$ is used to express vesting period and $T_{\text {exp }}$ is used to express maturity time (vesting period is included).

This binomial method begins with a simple stock price movement model. Stock price movements for a certain time interval which can increase or decrease. The time interval $\left[0, T_{\text {exp }}\right]$ is divided into $N$ sub intervals which are equal in length to the dividing points $0=t_{0}<$ $t_{1}<t_{2}<\cdots<T<\cdots<T_{N}=T_{\text {exp }}$ with $t_{n}=n . \Delta t$ $(n=0,1,2, \ldots, N), \Delta t=\frac{T_{\text {exp }}}{N}, S_{n}=S\left(t_{n}\right)$ as stock price at time $t_{n}$.

Some assumptions which are used in the binomial method are

a. In time $\Delta t$, the stock price probably go up or go down as follows : $S \rightarrow S u$ or $S \rightarrow S d$ with $0<$ $d<1<u$

b. The probability of the stock price up is $P(u p)=p$

c. The expected return on the price of the stock is equal to the free-risk interest rate $r$. Therefore, the stock price $S$ which moves randomly from $S_{n}$ to $S_{n+1}$ is

$$
\mathbb{E}\left(S_{n+1}\right)=S_{n} e^{(r-q) \Delta t}
$$

The parameters $u, d$, and $p$ will be determined after there are equations connecting the three assumptions or with an additional assumption. Based on assumption (a) and (b), the discrete model is obtained as follows.

$$
\mathbb{E}\left(S_{n+1}\right)=S_{n} p u+S_{n}(1-p) d
$$

From equation (1) and (2), we have

$$
S_{n} e^{(r-q) \Delta t}=S_{n} p u+S_{n}(1-p) d
$$

It gives

$$
p=\frac{e^{(r-q) \Delta t}-d}{u-d}
$$

To fulfill $0 \leq p \leq 1$ then it must be $d \leq e^{(r-q) \Delta t} \leq u$ From the continuous model, we get

$$
\mathbb{E}\left(S_{n+1}^{2}\right)=S_{n}^{2} e^{\left\{2(r-q)+\sigma^{2}\right\} \Delta t}
$$

Therefore

$$
\operatorname{Var}\left(S_{n+1}\right)=S_{n}^{2} e^{2(r-q) \Delta t}\left(e^{\sigma^{2} \Delta t}-1\right)
$$

From discrete model, we get

$$
\mathbb{E}\left(S_{n+1}^{2}\right)=p\left(S_{n} u\right)^{2}+(1-p)\left(S_{n} d\right)^{2}
$$

Therefore

$$
\operatorname{Var}\left(S_{n+1}\right)=p S_{n}^{2} u^{2}+(1-p) S_{n}^{2} d^{2}-S_{n}^{2}(p u+
$$

By setting the variance of the continuous model and the discrete model, namely from equations (4) and (5), we get

$$
\begin{aligned}
S_{n}^{2} e^{2(r-q) \Delta t}\left(e^{\sigma^{2} \Delta t}\right. & -1) \\
& =p S_{n}^{2} u^{2}+(1-p) S_{n}^{2} d^{2} \\
& -S_{n}^{2}(p u+(1-p) d)^{2}
\end{aligned}
$$

it gives us

$$
p=\frac{e^{\left\{2(r-q)+\sigma^{2}\right\} \Delta t}-d^{2}}{u^{2}-d^{2}}
$$

Equations (3) and (6) give the relationship between $u$, $d$, and $p$. Among the various possible options, which will be used are :

$$
\begin{array}{rl}
u d=1 & u=\frac{1}{d} \\
d_{1,2} & \approx e^{ \pm \sigma \sqrt{\Delta t}}
\end{array}
$$

Since $d \leq e^{(r-q) \Delta t} \leq u$ holds, then

$$
d=e^{-\sigma \sqrt{\Delta t}} \text { and } u=e^{\sigma \sqrt{\Delta t}}
$$

Suppose at time $t_{0}=0$ the stock price is $S_{0}$ then by the binomial method, the stock price at time $t_{1}$ is $S_{0} u$ or $S_{0} d$. Furthermore, the stock price at $t_{2}$ then the possible stock price is $S_{0} u^{2}$ or $S_{0} u d$ or $S_{0} d^{2}$. If this process is continued until $t_{n}=n \Delta t$ the stock price $S_{n, j}$ will be obtained as follows

$$
S_{n, j}=S_{0} u^{j} d^{n-j}
$$


With

$$
\begin{aligned}
& j=0,1,2, \ldots, n \\
& n=1,2,3, \ldots, N
\end{aligned}
$$

Let $V_{n, j}$ represents the ESO price at point $(n, j)$ and when $n=N_{V}$ represents the end of the vesting period. The ESO value at $t_{0}$ is expressed by $V_{0}$ and $D$ is

$$
D=\frac{V_{0}}{S_{0}}
$$

$\lambda$ States as the exit rate in the period $\Delta t$ so that the employee's probability of leaving the company is $\lambda \Delta t$ and the employee's opportunity to continue working in the company is $(1-\lambda \Delta t)$.

If the option is exercised, then in the next period, namely $t_{n+1}$ when the option has gone through the vesting period and it is in the money, the ESO recipient will get a new option $\rho_{H}$. It is because of the reload feature with the price $\rho_{H} S_{0} D$ which is the same as the price $S_{n+1, j}-K$. If the stock price falls until it hits the reset barrier $l K$, then each option will be replaced by a new $\rho_{L}$ option due to the reset feature with a price of $\rho_{L} l K D$. Furthermore, ESO prices will be calculated in the two time areas, namely after the vesting period and during the vesting period with the rules that apply therein.

\section{ESO Price}

\subsection{ESO Price after vesting Period}

There are two possibilities for employee condition. They will stay in the company or they will leave the company for some reasons. If they prefer to stay in the company with an opportunity of $(1-\lambda \Delta t)$ then the ESO price is divided into two, namely if at the time of exercise the stock price has reached the exercise boundary, the option price will be given by

$$
(1-\lambda \Delta t) \cdot \max \left(1_{\left\{S_{n, j} \geq K\right\}}\left(S_{n, j}-K+\rho_{H} S_{0} D\right)\right)
$$

However, if at the time of exercise the stock price does not reach the exercise boundary, the ESO price will be given by

$$
(1-\lambda \Delta t) \cdot\left(e^{-r \Delta t}\left(p V_{n+1, j+1}+(1-p) V_{n+1, j}\right)\right) .
$$

Hence, in case of an employee not leaving the company, the ESO price is given by

$$
\begin{aligned}
(1-\lambda \Delta t) \max \left(1 _ { \{ S _ { n , j } \geq K \} } \left(S_{n, j}-K\right.\right. \\
\left.+\rho_{H} S_{0} D\right), e^{-r \Delta t}\left(p V_{n+1, j+1}\right. \\
\left.\left.+(1-p) V_{n+1, j}\right)\right)
\end{aligned}
$$

Whereas, if the employee leaves the company with an opportunity of $\lambda \Delta t$ then the employee will not get a reload option therefore the ESO price corresponding to this case is

$$
\begin{array}{r}
(\lambda \Delta t) \cdot e^{-r \Delta t}\left(p\left(S_{n+1, j+1}-K\right)^{+}\right. \\
\left.+(1-p)\left(S_{n+1, j}-K\right)^{+}\right)
\end{array}
$$

Of these two possible conditions, giving the ESO price after the vesting period is

$$
\begin{gathered}
V_{n, j}=(1-\lambda \Delta t) \cdot \max \left(1 _ { \{ S _ { n , j } \geq K \} } \left(S_{n, j}-K+\right.\right. \\
\left.\left.\rho_{H} S_{0} D\right), e^{-r \Delta t}\left(p V_{n+1, j+1}+(1-p) V_{n+1, j}\right)\right)+ \\
(\lambda \Delta t) \cdot e^{-r \Delta t}\left(p\left(S_{n+1, j+1}-K\right)^{+}+(1-p)\left(S_{n+1, j}-\right.\right.
\end{gathered}
$$$$
\mathrm{K})^{+} \text {) }
$$

Where $\mathrm{j}=\mathrm{N}-1, \mathrm{~N}-2, \ldots, \mathrm{N}_{\mathrm{V}}$

If the ESO price is at or below the barrier $l K$ then the ESO price will be replaced by $\rho_{L} l K D$.

\subsection{ESO price at vesting period}

There are also two possibilities condition may occur with the employee at vesting period, whether they will leave the company or they will stay with the company. If the employee does not leave the company with a probability of $(\mathbf{1}-\boldsymbol{\lambda} \Delta \boldsymbol{t})$ then the ESO price is given by

$$
(1-\lambda \Delta t) \cdot e^{-r \Delta t}\left(p V_{n+1, j+1}+(1-p) V_{n+1, j}\right)
$$

Whereas, if the employee leaves the company with an opportunity of $\boldsymbol{\lambda \Delta t}$, the employee will not get compensation for the ESO. It will be declared forfeited for their ESO. The ESO value corresponding to this case is $(\boldsymbol{\lambda} \Delta \boldsymbol{t}) . \mathbf{0}$

Of these two conditions that may occur, giving the ESO price at the time of the vesting period is

$$
\begin{gathered}
V_{n, j}=(1-\lambda \Delta t) \cdot e^{-r \Delta t}\left(p V_{n+1, j+1}+(1-p) V_{n+1, j}\right) \\
+(\lambda \Delta t) .0
\end{gathered}
$$

Meanwhile, if the ESO price is at or below the barrier $\boldsymbol{l K}$ then the ESO price will be replaced by $\boldsymbol{\rho}_{L} \boldsymbol{l K} \boldsymbol{D}$

\subsection{The valuation of ESO}

Here, the simulation of the valuation of ESO price for several parameters given.

Tabel 1. The valuation of ESO pric

\begin{tabular}{|c|c|c|c|c|c|c|c|c|c|c|c|c|}
\hline $\boldsymbol{S}$ & $\boldsymbol{K}$ & $\boldsymbol{r}$ & $\boldsymbol{\sigma}$ & $\boldsymbol{q}$ & $\boldsymbol{\lambda}$ & $\boldsymbol{\rho}_{H}$ & $\boldsymbol{\rho}_{\boldsymbol{L}}$ & $\boldsymbol{T}_{\text {vest }}$ & $T_{\exp }$ & $\boldsymbol{l}$ & $\boldsymbol{N}$ & ESO Price \\
\hline 80 & 80 & 0.04 & 0.4 & 0.02 & 0.2 & 1 & 1 & 2 & 10 & 0.6 & 1000 & 27.0456 \\
\hline 60 & 60 & 0.03 & 0.3 & 0.015 & 0.15 & 1 & 1 & 1.5 & 10 & 0.6 & 1500 & 21.4312 \\
\hline 50 & 50 & 0.03 & 0.2 & 0.01 & 0.1 & 1 & 1 & 2 & 10 & 0.6 & 2000 & 16.667 \\
\hline 25 & 25 & 0.03 & 0.2 & 0.01 & 0.1 & 1 & 1 & 2 & 10 & 0.6 & 2000 & 8.3335 \\
\hline
\end{tabular}

\section{Conclusion}

The valuation of ESO price with some features such as vesting period, exit rate, reload and reset have been obtained through five possibilities of payoff diagram. It gives two area of price, which are ESO price after 
vesting period and ESO price at vesting period. The ESO price after the vesting period is

$$
\begin{aligned}
\mathrm{V}_{\mathrm{n}, \mathrm{j}}=(1-\lambda \Delta \mathrm{t}) . & \max \left(1 _ { \{ \mathrm { s } _ { \mathrm { n } , \mathrm { j } } \geq \mathrm { K } \} } \left(\mathrm{S}_{\mathrm{n}, \mathrm{j}}-\mathrm{K}\right.\right. \\
& \left.+\rho_{\mathrm{H}} \mathrm{S}_{0} \mathrm{D}\right), \mathrm{e}^{-\mathrm{r} \Delta \mathrm{t}}\left(\mathrm{p} \mathrm{V}_{\mathrm{n}+1, \mathrm{j}+1}\right. \\
& \left.\left.+(1-\mathrm{p}) \mathrm{V}_{\mathrm{n}+1, \mathrm{j}}\right)\right) \\
& +(\lambda \Delta \mathrm{t}) \cdot \mathrm{e}^{-\mathrm{r} \Delta \mathrm{t}}\left(\mathrm{p}\left(\mathrm{S}_{\mathrm{n}+1, \mathrm{j}+1}-\mathrm{K}\right)^{+}\right. \\
& \left.+(1-\mathrm{p})\left(\mathrm{S}_{\mathrm{n}+1, \mathrm{j}}-\mathrm{K}\right)^{+}\right)
\end{aligned}
$$

If the ESO price is at or below the barrier $l K$ then the ESO price will be replaced by $\rho_{L} l K D$. is

Whereas, the ESO price at the time of vesting period

$$
\begin{gathered}
V_{n, j}=(1-\lambda \Delta t) \cdot e^{-r \Delta t}\left(p V_{n+1, j+1}+(1-p) V_{n+1, j}\right) \\
+(\lambda \Delta t) \cdot 0
\end{gathered}
$$

if the ESO price is at or below the barrier $l K$ then the ESO price will be replaced by $\rho_{L} l K D$

\section{References}

[1] Bryson, Alex, and Richard B. Freeman. "The role of employee stock purchase plans-gift and incentive? Evidence from a multinational corporation." British Journal of Industrial Relations 57.1 (2019): 86-106

[2] Asyik, Nur Fadjrih. "Dampak Struktur Modal Pada Sensitivitas Penerapan Kompensasi Opsi Saham Karyawan Terhadap Kinerja." EKUITAS (Jurnal Ekonomi dan Keuangan) 14.1 (2010): 1-21.

[3] Bergman, Nittai K., and Dirk Jenter. "Employee sentiment and stock option compensation." Journal of financial Economics 84.3 (2007): 667-712.

[4] Cappelli, Peter, Martin Conyon, and David Almeda. "Social exchange and the effects of employee stock options." ILR Review 73.1 (2020): 124-152.

[5] Core, John E., and Wayne R. Guay. "Stock option plans for non-executive employees." Journal of financial economics 61.2 (2001): 253-287.

[6] Kraus, Herbert. Executive Stock options and Stock appreciation rights. Law Journal Press, (2021).

[7] Lazear, Edward P. "Compensation and Incentives in the Workplace." J. of Eco. Persp. 32.3 (2018): 195-214.

[8] Gerakos, Joseph J., Christopher D. Ittner, and Frank Moers. "Compensation objectives and business unit pay strategy." $J$. of Manag. Acc. Res 30.2 (2018): 105-130.

[9] Rosen, Corey, and Karen M. Young, eds. Understanding employee ownership. Cornell University Press, 2018.

[10]Rosen, Corey. "1. Employee Ownership: Performance, Prospects, and Promise." Understanding employee ownership. Cornell University Press, 2018. 1-42.

[11] Oehmichen, Jana, Michael Wolff, and Ulrike Zschoche. "Employee participation in employee stock ownership plans: Cross-level interaction effects of institutions and workgroup behavior." Human Resource Management 57.5 (2018): 1023-1037.

[12] Javed, Tariq, and S. Idris. "Impact of employee ownership on an organizational productivity: A mediating role of psychological ownership." Academy of Accounting and Financial Studies Journal 22.2 (2018): 1-12.

[13] Aldatmaz, Serdar, Paige Ouimet, and Edward D. Van Wesep. "The option to quit: The effect of employee stock options on turnover." Journal of Financial Economics 127.1 (2018): 136-151.

[14]Blasi, Joseph, Douglas Kruse, and Richard B. Freeman. "Broad-based employee stock ownership and profit sharing: History, evidence, and policy implications." Journal of Participation and Employee Ownership (2018).

[15] Sircar, Ronnie and Xiong, Wei. (2006), A general Framework for Evaluating Executive Stock Options, Journal of Economic Dynamics \& Control 31, 2317-2349 